\title{
Concepções de uma eQuipe multidisciplinar sobre fuga de pacientes
}

\author{
Concepts of a multidisciplinar team on runaway patients
}

Las concepciones de un equipo multiprofesional acerca de fugas del paciente

\author{
Sílvio Antônio Vieira', Clarice Maria Dall'Agnol' \\ 'Universidade Federal do Rio Grande do Sul. Escola de Enfermagem. Porto Alegre, RS
}

Submissão: 2 1/1 1/2007

Aprovação: 22/10/2008

\section{RESUMO}

Estudo de abordagem Qualitativa com o objetivo de apreender como uma equipe multidisciplinar de um serviço de emergência em um hospital universitário público concebe e transita ante o problema fuga de pacientes do hospital. A coleta de dados, por meio da técnica de grupos focais, consolidou-se com dez sujeitos, tendo-se implementado uma dinâmica grupal não diretiva. Três categorias temáticas resultaram da análise de conteúdo: uma certa ambivalência, emergência: um local de (des)controle, e, medos e inseguranças. O estudo aponta para a condição caótica com Que se deparam os serviços de emergência e, nesse contexto, os profissionais da equipe de saúde, mediante a fuga de pacientes, vêem-se na iminência de um triplo julgamento: o social, o jurídico e o institucional.

Descritores: Gestão em saúde; Administração de serviços de saúde; Desistência do paciente; Serviço hospitalar de emergência; Grupos focais.

\section{ABSTRACT}

A Qualitative study that aimed at learning the way an emergency care multidisciplinary team at a public university hospital conceives and deals with the problem of patients who run away from hospital was carried out. Data were collected using the focus groups technieue, whose sample was constituted by ten individuals, approached by non-directive group dynamics. Three thematic classes resulted from content analysis: a certain ambivalence; emergency, a place of (lack of) control; fears and insecurities. The study indicates the chaotic situation encountered by emergency services and, in this context, when patients run away, the health care team is imminently subject to a triple judgment: social, legal and institutional.

Descriptors: Health management; Health services administration; Patient dropouts; Emergency service hospital; Focus groups.

\section{RESUMEN}

Abordaje cualitativo, exploratorio, con el objetivo de aprehender como un equipo multidisciplinar de un servicio de emergencia, en un hospital universitario público, concibe y se enfrenta con el problema de huida de pacientes del hospital. La recolección de datos, por medio de la técnica de grupos focales, se consolidó con diez sujetos, implementándose una dinámica grupal no directiva. Tres categorías temáticas resultaron del análisis de contenido: una cierta ambivalencia; emergencia, un local de (des)control; miedos e inseguridades. El estudio apunta a la condición caótica con que se deparan los servicios de emergencia y, en ese contexto, los profesionales del equipo de salud, delante de la huida de pacientes, se ven en la inminencia de un triple juzgamiento: lo social, lo jurídico y lo institucional Descriptores: Gestión en salud; Administración de los servicios de salud; Desistencia del paciente; Servicio de urgencia en hospital, Grupos focales. 


\section{INTRODUÇÃO}

Em nossa trajetória profissional, temos verificado que fuga de pacientes é um discurso Que permeia a ambiência hospitalar, marcadamente nos serviços de emergência, sendo um tema ainda nebuloso e, como tal, vem sugerindo percepções divergentes e, por vezes, unilaterais ou até mesmo contraditórias, entre os atores organizacionais, atraindo diversos olhares.

Tendo disparado uma busca sistematizada sobre o tema, viu-se Que esta condição remete à insuficiência de informações acerca do mesmo nos próprios conselhos profissionais dos trabalhadores em saúde, tanto Que a Questão da fuga, na área médica, é tratada de maneira pontual na especialidade de psiquiatria. Ao revisar o Código de Ética e Deontologia de Enfermagem, deparou-se com ausência de matéria, tanto no âmbito do Conselho Federal de Enfermagem $(\mathrm{COFEN})^{(1)}$ como no Conselho Regional de Enfermagem (COREN/ $\mathrm{RS})^{(2)}$, tornando relevante a discussão.

No âmbito dos hospitais gerais, a preocupação com fuga de pacientes consta em anotações feitas pelos respectivos serviços de segurança. Como exemplo, citam-se os registros em boletim do Hospital de Clínicas da Universidade de Campinas - UNICAMPQue, em 1999, acusou uma incidência de $28 \operatorname{casos}^{(3)}$. No Serviço de Emergência do Hospital de Clínicas de Porto Alegre, o número de fugas chegou a aproximadamente 70 em junho de 2002, causando preocupação aos enfermeiros do setor ${ }^{(4)}$.

Em certa ocasião, em uma reunião administrativa do campo, houve recomendação por parte da chefia do serviço de enfermagem Que os enfermeiros, ao realizarem notificações ao serviço de segurança do hospital, por meio de boletins de atendimento, registrassem as seguintes observações: "fuga com risco de vida" ou "fuga sem risco de vida". Então, foram solicitadas sugestões a respeito do Que poderia / deveria ser feito, visando a redução dos índices de fuga, tendo-se adotado um cartão de autorização para entrada e saída do paciente adulto Que era atendido na sala de procedimentos, no interior da emergência. O livre trânsito do paciente ocorria mediante apresentação desse cartão ao funcionário do serviço de segurança, na porta de acesso da emergência. Um viés desta rotina é o fato de caracterizar indevidamente algumas ausências como fuga do hospital. Assim, os motivos dos pacientes Que os levavam à suposta fuga poderiam estar sinalizando focos da problemática na própria dinâmica de trabalho. Refletir sobre tais Questões, entre os enfermeiros, foi propulsor no sentido de ampliar o espectro de compreensão, com o assinalamento de Que as práticas em saúde e enfermagem muitas vezes se colocam em uma analogia simbólica com as práticas carcerárias. Outras manifestações com relação à fuga do pacientes eram direcionadas no sentido de associá-la diretamente à superlotação, condição bastante peculiar em se tratando dos serviços de emergência.

Estas e outras ponderações, desde logo, apontaram para a Questão da fuga como uma problemática Que não se restringe à área de enfermagem, porém, diz respeito aos diversos profissionais Que compõem as equipes multiprofissionais, na medida em Que o cuidado se efetiva a partir da relação de interdependência Que se estabelece entre os mesmos. Assim, o objetivo do estudo consistiu em apreender como a equipe multidisciplinar do serviço de emergência de um hospital público de Porto Alegre concebe e transita ante o problema fuga de pacientes do hospital.

\section{REFERENCIAL TEÓRICO}

Uma das características da pós-modernidade, também chamada de modernidade pós-panóptica, é o fim da era do engajamento mútuo: entre supervisores e supervisionados, capital e trabalho, líderes e seguidores, exércitos em guerra ${ }^{(5)}$. A era pós-panóptico anuncia novas técnicas de poder: a fuga, a astúcia, o desvio e a evitação. Pensa-se Que a realidade Que permeia o espaço das organizações hospitalares, especificamente dos serviços de emergência, está diante da confusão de fronteiras Que se estabelece entre a sociedade de controle e vigilância da era moderna, representada pelo panóptico foucaultiano, e a modernidade póspanóptica, representada pelo desengajamento e pela fuga.

Embora não tenhamos aderido ao método arqueológico propriamente, enquanto desenho de pesquisa Que remeteria a uma condição peculiar de análise de discurso, houve uma aproximação significativa deste referencial, especialmente no Que tange à abordagem foucaultiana. Com base neste aporte teórico, os principais eixos de discussão foram conduzidos a partir das discursividades locais. Ao vivenciar a realidade do serviço de emergência, vêem-se casos em Que pacientes e equipe multidisciplinar são submetidos não somente ao discurso hospitalocêntrico, mas também ao discurso jurídico-legal, tornandose além de sujeitos, sujeitados às relações Que se estabelecem. $\mathrm{O}$ hospital é a grande instituição onde só devem circular diagnósticos precisos, onde operam relações de saber e poder, onde o vigiar torna-se a representação do sistema panóptico.

O panóptico - construção arQuitetônica idealizada por Bentham - representa a forma institucional carcerária ou não de instituições estatais ou não, impondo à sociedade idéias de disciplina, vigilância, punição e segurança. Assim, "cada vez Que se tratar de uma multiplicidade de indivíduos a Que se deve impor uma tarefa ou um comportamento, o esQuema panóptico poderá ser utilizado"(6), aplicando-se a todos os estabelecimentos, mantendo-se sob vigilância certo número de pessoas.

Nestas organizações, também nomeadas de instituições no referencial foucaultiano, tais como hospitais, escolas, universidades, penitenciárias e fábricas, seus dirigentes se delegam o direito de dar ordens, de estabelecer regulamentos, de tomar medidas, de expulsar indivíduos e de aceitar outros ${ }^{(7)}$, reforçando a presença de um discurso centrado em idéias de ordem, vigilância e disciplina.

A compreensão das práticas discursivas e de discurso em Foucault são essenciais às reflexões Que podem associar-se ao objeto em estudo. Neste aspecto, ressalta-se Que "as práticas discursivas não são pura e simplesmente modos de fabricação de discursos. Ganham corpo em conjuntos técnicos, em instituições, em esQuemas de comportamento, em tipos de transmissão e de difusão, em formas pedagógicas, Que ao mesmo tempo as impõem e as mantêm"(8).

As práticas discursivas Que acontecem em meio a instituição hospitalar, inseridas e circulando nas relações profissionais Que se estabelecem no serviço de emergência, podem produzir saberes e verdades, não somente sustentado pelo discurso clínico-biologicista, mas integrando-se ou amarrando-se ao discurso jurídico-legal. $\mathrm{O}$ discurso em pauta refere-se à fuga de pacientes nesse local de trabalho, assim como práticas discursivas podem ser caracterizadas por normas e rotinas Que se estabeleceram ante o problema, tendo 
como exemplo a notificação para o serviço de segurança após constatação de fuga de paciente. Concomitantemente, tal prática remete à idéia de conduta, conotando ainda Que no ato de conduzir existem relações de poder, oportunizados por mecanismos de coerção mais ou menos estritos, indicando maneiras de se comportar e relacionar ante a busca de uma provável ordem ${ }^{(9)}$. Desta forma, métodos administrativos importaram para dentro das organizações inúmeros dispositivos e técnicas de controle do campo da política e das instituições totais, reforçando a idéia de um pensamento administrativo Que procura técnicas de dominação e de consenso ${ }^{(10)}$. Diante dessas considerações, pode-se Questionar: de Quem ou de Quê os pacientes fogem? Como a equipe multidisciplinar percebe e age ante o problema? Que discursos estão em jogo? Que relações de saber e poder estão em jogo?

\section{METODOLOGIA}

Estudo de abordagem Qualitativa com o intuito de "desenvolver, esclarecer e modificar conceitos e idéias, tendo em vista, a formulação de problemas mais precisos ou hipóteses pesQuisáveis para estudos posteriores"(1 I). A coleta de dados utilizou a Técnica de Grupos Focais e transcorreu no período entre novembro e dezembro de 2004, junto ao serviço de emergência de um hospital de Porto Alegre, Rio Grande do Sul, cujo detalhamento é apresentado a seguir.

\section{Local e Sujeitos de Pesquisa}

Trata-se de um hospital universitário público, geral, pertencente à rede de hospitais do Ministério da Educação e vinculado à Universidade Federal do Rio Grande do Sul (UFRGS). Dispõe de 103.310,8m² de área construída e 641 leitos de internação ${ }^{(12)}$, dos Quais 23 estão alocados no setor de Emergência. Este localizase no andar térreo, numa área aproximada de $1.000 \mathrm{~m}^{2}$, mantendo em suas instalações atendimento para adultos em clínica geral, cirurgia geral e ginecologia e atendimento pediátrico nas modalidades clínica e cirúrgica. A sala de procedimentos conta com instalação de doze cadeiras, contudo, diariamente, pacientes são acomodados em cadeiras extras - do tipo de escritório ou de rodas - dispostas ao longo dos corredores de acesso próximos a esta sala. A sala de observação de adultos, com instalação para Quinze leitos, vem mantendo leitos / macas extras, chegando até o número de 37 acomodações.

Quanto aos sujeitos da peseuisa, contou-se com 12 profissionais da equipe de saúde, todos atuantes no Serviço de Emergência, tendo-se agregado médicos, enfermeiros, técnicos de enfermagem, seguranças, auxiliar administrativo e assistente social. A escolha dos sujeitos foi intencional, adotando-se o critério de interesse em discutir a temática, seguindo perspectiva já adotada em outros estudos $^{(13-15)}$. Para composição do módulo desejado, recorreu-se à estratégia snowball technique ${ }^{(16)}$, convidando-se inicialmente um informante-chave de cada modalidade profissional e a cada um destes solicitava-se a indicação de mais um colega, entre seus pares, para participar da pesquisa. $\mathrm{Na}$ impossibilidade de algum dos sujeitos, buscava-se nova indicação, até preencher o módulo previsto, assegurando presença mínima de dois representantes de cada categoria profissional, exceto no caso do auxiliar administrativo e assistente social Que se limitaram à representação única, em razão do exíguo contingente numérico dessas categorias no setor e o respectivo interesse em participar da pesquisa.

\section{Grupos Focais como Técnica para a Coleta de Dados}

O grupo focal "é um método de pesquisa Que pode ser utilizado no entendimento de como se formam as diferentes percepções e atitudes acerca de um fato, prática, produto ou serviços"(17) e é apoiado na interação entre seus participantes para a coleta de dados, mediante discussões previamente planejadas, conforme preconiza a literatura ${ }^{(14)}$.

Houve seis encontros semanais, gravados em áudio, cada um com duração aproximada de uma hora e trinta minutos, Que ocorreram no período entre novembro e dezembro de 2004. As atividades eram realizadas em uma sala no interior do Serviço de Emergência, garantindo privacidade, conforto e fácil acesso do grupo, sendo Que este agregou 12 participantes, cuja composição já foi explicitada na descrição do campo. Por ocasião do setting, momento caracterizado como o contrato grupal ${ }^{(14)}$, acordou-se acerca do compromisso de cada participante em manter o caráter confidencial dos debates. Outras combinações foram feitas como a comunicação prévia entre os membros do grupo sobre eventuais ausências, buscando assegurar o Quorum de cada encontro. Registra-se Que houve presença integral no primeiro e último encontro e, nos demais, contou-se com pelo menos sete participações, em razão das possibilidades presenciais.

O tema disparador dos debates consistiu em Questionar o grupo como vinha percebendo e agindo ante o problema fuga dos pacientes. Como estratégia para retomada e aquecimento das discussões nos momentos seguintes, a equipe de coordenação, composta pelo moderador dos debates (um dos pesquisadores) e uma observadora participante (psicóloga), reunia-se sistematicamente antes e depois de cada sessão grupal, com o intuito de preparar o aquecimento das discussões subseqüentes. Destaca-se Que a inclusão de uma observadora participante na execução da Técnica de Grupos Focais foi muito importante para balizar os desfechos relativos aos debates, principalmente em razão do perfil da pessoa selecionada para assumir este papel, pois a mesma já tinha experiência prévia como observadora participante de outras pesquisas similares e, além disso, apresentava domínio do referencial teórico Que deu suporte à dinâmica grupal.

\section{Aspectos Éticos}

O projeto foi submetido à apreciação do Comitê de Ética em Pesquisa do Hospital de Clínicas de Porto Alegre, onde obteve homologação, sob número 04-387, tendo-se atendido à Resolução 196/96 do Conselho Nacional de Saúde Que versa sobre precauções éticas em pesQuisas com seres humanos ${ }^{(18)}$. Somente em posse do parecer favorável, deu-se início à coleta de dados, sendo apresentado o Termo de Consentimento Livre e Informado a cada sujeito, cujo documento foi assinado pelas partes envolvidas, em duas vias, ficando uma com o participante e outra com o pesQuisador. Destaca-se Que as fitas magnéticas relativas à gravação em áudio das sessões de Grupos Focais foram inutilizadas, procedendo-se à guarda do material transcrito, por cinco anos, a partir da publicação dos resultados.

Para preservar o anonimato e o caráter confidencial das informações, no tópico em Que se apresenta os resultados do 
estudo, mais adiante, as falas dos sujeitos são referidas como PI (Participante 1), P2 (Participante 2), P3 (Participante 3) e, assim, sucessivamente. Este ordenamento deu-se a partir da lista de adesão ao grupo focal, seguindo a inscrição cronológica das participantes.

\section{Análise dos Dados}

Após transcrição das fitas magnéticas, em forma de crônicas, fez-se leituras sucessivas do material, buscando-se apreender o fio condutor de cada sessão grupal. O material, no conjunto, foi submetido à análise de conteúdo, procedimento Que relaciona estruturas semânticas - significantes - com estruturas sociológicas - significados - dos enunciados ${ }^{(19)}$. Nesse percurso, também houve ancoragem nas ferramentas de análise foucaultianas - saber e poder - sendo criadas unidades de registro Que oportunizaram um sistema de classificação temático ${ }^{(20)}$.

\section{RESULTADOS E DISCUSSÃO}

A seguir, apresentam-se os resultados e a respectiva discussão, com desdobramento em três eixos centrais: Uma certa ambivalência; Emergência, um espaço de (des)controle; Medos e inseguranças.

\section{Uma Certa Ambivalência}

Fuga de pacientes do hospital suscitou discussões e reflexões Que se associaram ao número excessivo de pacientes atendidos nas dependências do setor, principalmente na sala de procedimentos destinada aos adultos, sendo motivo para a seguinte declaração:

Nós também fugimos [...] através dos encontros seguidos no café [...]. (PI).

Muitas Questões remeteram à ambivalência do significado e à forma com Que a palavra fuga foi sendo empregada pela equipe multidisciplinar desse serviço. As saídas para tomar café, Que os sujeitos nominam de fuga, podem ser compreendidas como um "respiradouro" ou, Quem sabe, estivesse sinalizando evitação. Outra ressignificação foi verificada nas práticas do serviço de segurança. Segundo um dos participantes, os casos ocorridos nas unidades de internação são apontados em livro próprio de ocorrências e registrados em Delegacia de Polícia e são tratados institucionalmente como fuga. Os casos da Emergência, Que são vistos como evasão, somente seguem esta última tramitação se houver comunicação de risco à vida.

A situação torna-se ambivalente Quando lingüisticamente há uma estruturação inadeQuada, não pertencendo a uma única situação, Quando a discriminação recai em várias classes ao mesmo tempo ${ }^{(21)}$. No entanto, concomitantemente, percebeu-se a presença de jogos lingüísticos ou estratégicos com Que se apresentaram os discursos - de ação e de reação, de pergunta e resposta, de dominação e esquiva. Mas, sobretudo, de luta e imposição de significados ${ }^{(7)}$.

Uma certa banalização destas fugas foi percebida em algumas falas. Assim, surgiu nas discussões:

\section{É menos um na lista da sala de procedimentos (P3).}

A banalização Que ocorre pode ser associada ao aumento do número de atendimentos Que os vários sujeitos desta equipe multidisciplinar enfrentam no dia-a-dia desse ambiente de cuidado.

\section{Emergência, um Lugar de (des)Controle}

Em um dos encontros, um dos participantes fez o seguinte Questionamento:

O Quê vocês acham: é ético, é elegante, é necessário aQueles adesivos que vocês colocam nas costas dos velhinhos? (PI).

A pergunta refere-se aos adesivos Que são feitos de esparadrapo, pela equipe de enfermagem, colocados nas costas dos pacientes, informando literalmente "Risco de Fuga". Os pacientes Que apresentam este risco são portadores de Quadros de demência, confusão e/ou desorientação e permanecem no setor sem a presença de acompanhantes. No entanto, há aQueles Que não se enQuadram nesta caracterização, sinalizando muitas vezes, apenas, o seu desejo de não permanecer mais na Emergência. Por isso, foi dito:

Eles avisam que vão fugir [...]. Começam a caminhar de um lado a outro [...] procurando uma saída. (P5).

Após intensa discussão do grupo, foi pontuada como necessária esta prática, tendo em vista a responsabilização ético-profissional, em casos de eventuais processos jurídicos. Mas, também, foi trazida para a pauta das discussões a conduta de vigilância e controle dos pacientes com risco de fuga, havendo oferta extra de alimentos para outros pacientes Que podem auxiliar na observação daQueles Que apresentam este risco:

Quando o paciente " $X$ " está na sala de procedimentos [...] Eu dou dois cafés para ele cuidar de algum velhinho Que está sozinho [...]. (P3).

Esta fala remete a considerar a estreita identificação de singularidades Que demarcam o espaço da emergência com aQuelas descritas por Foucault sobre o panóptico de Bentham ${ }^{(6)}$ O panóptico de Bentham é uma construção com função de vigilância carcerária Que foi adaptada para outros tipos de instituições: escolas, hospitais, fábricas, entre outros, pouco importando Quem exerce o poder de vigiar. No caso deste estudo, o poder de delegar também é exercido pelos enfermeiros, não importando Quem deverá vigiar ou observar os possíveis pacientes fugitivos.

Conforme dados do serviço de segurança do Hospital, o número de fugas na Emergência é muito superior aos dos setores de internação. Em um dos encontros do grupo focal, constatou-se Que as informações Que circulavam entre o serviço de segurança e a área administrativa e chefia de enfermagem não eram de conhecimento da maioria dos profissionais do próprio setor. Este fato sinalizou a ocorrência de falhas de comunicação, principalmente no Que tange à circulação de informações gerenciais, no Hospital.

A idéia de controle, através de planilha mensal contendo o número de fugas do hospital, remete a pensar sobre achados na literatura ${ }^{(22)}$ Quanto aos indicadores de Qualidade da assistência prestada, na medida em Que estes também devem considerar a Quantidade. Assim, em razão da complexidade da área hospitalar, é requerida a criação de outros indicadores Que possibilitem medir 
e avaliar tecnologicamente os eventos-sentinela, tais como: mortes imprevistas de pacientes, surtos de infecção hospitalar, cirurgia em paciente errado, reações transfusionais, entre outros No tópico designado como "outros" foram incluídas as fugas de pacientes, ficando a ressalva de Que os eventos-sentinela sugerem referência à organização ou desorganização dos serviços de saúde ${ }^{(22)}$, mas, também reforçam a idéia de Que o hospital é uma instituição Que tem por objetivo curar indivíduos por meio de ações de controle e disciplinamento.

A organização do serviço e o processo de trabalho foram muitas vezes citados, nas discussões do grupo focal, em Que surgiram associações desta problemática com Questões referentes ao trabalho realizado por médicos e equipe de enfermagem na sala de procedimentos de adultos:

Ali é a maior confusão [...] tu não tens controle das coisas [...].(P4).

Houve referências a uma prática cultural, institucionalizada pelas várias equipes médicas do hospital, de transferir para a Emergência os pacientes com problemas Que não são facilmente resolvidos nos setores de ambulatório. Assim, o Serviço de Emergência não se tornou somente porta de entrada para o sistema hospitalar, ele é um "depositório", ficando a idéia simbólica de "campo de concentração" para a equipe multidisciplinar:

Aqui no hospital é assim: Qualeuer problema [...] leva pra emergência! Está mal? Leva pra emergência! A emergência é o depositório de toda essa Questão [...]. Assim, dessa tentativa de fugir dos problemas.(PI).

Quando a gente vê as pessoas mutiladas, sentadas, uns com máscara [...] se tem a sensação de ver a Emergência como um campo de concentração. (P 7).

A expressão utilizada pelo participante 7 diz respeito aos pacientes que necessitam utilizar máscaras do tipo cirúrgicas e descartáveis como forma de proteção individual, como é caso de pacientes imunodeprimidos ou como forma de serem evitadas a propagação de doenças infecto-contagiosas, por exemplo, pacientes com suspeita ou portadores de tuberculose. Tal declaração reforça a representação contida na obra pictórica intitulada Emergency Room $^{(23)}$. Nessa obra, a multidão Que se concentra em uma sala de emergência constitui-se de pessoas nuas, sem privacidade, esfarrapadas, tratadas como carvão e sendo recolhidas por uma enfermeira. Na parte inferior da mesma obra pictórica, o pintor colocou a figura de um policial Que tenta parar o fluxo de pacientes e mais à esQuerda, mostra a chegada de uma ambulância ao serviço de emergência. Seria uma alusão do pintor ao Que conhecemos como "ambulancioterapia”, ou seja, o elevado número de ambulâncias - procedentes do interior e de outros Estados - Que transportam pacientes não atendidos em seus locais de origem e Que, invariavelmente, dirigem-se aos serviços de emergência de referência, como é o caso desse hospital? Cabe destacar Que, atualmente, os hospitais públicos têm sido sobrecarregados pela procura, atendendo demandas que extrapolam, em muito, aQuelas Que lhes competem, se levássemos em conta o geo-referenciamento e sua finalidade no sistema de saúde.

\section{Medos e Inseguranças}

Ao se discutir sobre a existência de um parecer da consultoria jurídica sobre fuga de pacientes da emergência, documento de uso interno no Hospital, evidenciou-se novamente o medo e a insegurança Que profissionais da área médica e de enfermagem têm de sofrerem algum processo de responsabilidade profissional. No grupo, surgiu o seguinte comentário:

Queria saber Qual o parecer jurídico [...]. Até onde vai a responsabilidade dos funcionários da emergência em relação a fuga? A responsabilidade é da instituição ? (PI).

Em material disponibilizado pelo Superior Tribunal de Justiça ${ }^{(24)}$ sobre matéria desta ordem, encontrou-se referências à fuga de paciente em hospital psieuiátrico tendo como desfecho o suicídio do paciente com surto psicótico. Ressalta-se Que a matéria julgada não estava diretamente relacionada à fuga de hospital geral. Tratase do que é chamado, em linguagem jurídica, de culpa in vigilando, caracterizada como falta de diligência, atenção, fiscalização ou QualQuer outro ato do agente, no cumprimento do seu dever e, de cujo ato, decorre prejuízo para outrem.

O parecer do Conselho Regional de Medicina de São Paulo dado à Consulta número 23.606/97 $7^{(25)}$ indicou Que a instituição hospitalar pode ser responsabilizada do ponto de vista jurídico pela fuga do paciente, face ao dever de vigilância contraído no ato de hospedar, independente do seu caráter gratuito ou oneroso. $\mathrm{O}$ medo relativo a processos ético-disciplinares que os participantes do grupo referiram, principalmente por parte de médicos e enfermeiros, é real. Levantamento realizado em 200 I $^{(26)}$ é ilustrativo, indicando aumento considerável do número de processos disciplinares nos conselhos profissionais. Tais depoimentos remetem-nos a reflexões que afirmam Que, além dos poderes econômicos e políticos, existe um poder judiciário nas relações Que se estabelecem intra-instituições ${ }^{(7)}$. Neste contexto, pensa-se Que a equipe multidisciplinar é passível de um triplo julgamento: o social, o jurídico e o institucional.

\section{CONSIDERAÇÕES FINAIS}

Além de fuga ou evitação, possivelmente outros significados pudessem ser desvelados. Isto é, até Que ponto não podemos entender a fuga como forma de desistência dos pacientes nos serviços de emergência ou instituições hospitalares?

Os profissionais, especialmente membros da equipe de enfermagem e de segurança, são os vigilantes. Quando o espaço se torna superlotado, integrantes da equipe de enfermagem delegam a vigilância a outros pacientes oferecendo-lhes alimentação a mais, em contrapartida.

Os casos de alta a pedido pouco foram citados, apesar de terem surgido nos debates do grupo focal. Contudo, desvelou-se certa confusão, em detrimento das responsabilidades profissionais. Com relação a isto, a equipe sabe como agir frente aos casos de pacientes Que demonstram, de uma forma ou de outra, Que vão fugir. Em suas práticas discursivas, é percebida a similaridade que ocorre entre práticas de cuidado e práticas carcerárias como constatado 
no ato de colocar um adesivo informando sobre o possível risco de fuga. Contudo, considerando que a maior parte dos pacientes Que fogem apresentam condições físicas e psíquicas adęuadas como verbalizado pelos membros da equipe - convém Questionar sobre a ausência de rotina administrativa que propicie a alta a pedido.

Em alguns momentos foi notória a identificação de membros da equipe com a situação vivenciada pelos pacientes. Tal fato sinalizou Que, além de suas posições de sujeito, enquanto profissionais da instituição, tornam-se compreensivos aceitando a fuga dos pacientes. No contexto atual, estas ações ou reações são os indicativos de aspectos paradoxais Que envolvem a situação.

Reflexões suscitaram discussões sobre os riscos de responsabilização profissional, não importando ao grupo se as medidas empregadas para evitar a fuga são pertinentes do ponto de vista da ética ou tão somente "elegantes". No contexto do estudo, a instituição hospitalar esforça-se para acomodar os pacientes. No entanto, os pacientes Que fogem não são os Que necessitam de maca, cama ou cadeira de rodas. Considerando Que as ações de assistência e cuidados prestados aos pacientes são dependentes de observação e controle, é aconselhável Que futuras reformas do ambiente físico dêem ênfase à maQuinaria panóptica. Constatou-se que parte dos profissionais da equipe multidisciplinar desconhecem que os casos de fugas na Emergência, ao contrário das unidades de internação, são tratados como casos de evasão pelo serviço de segurança do Hospital. No entanto, por sugestão da consultoria jurídica da instituição, os enfermeiros devem registrar no boletim de atendimento do paciente a ocorrência do fato para posterior registro no setor de segurança. Desta forma, é patente a preocupação institucional com a possibilidade de instauração de processos de responsabilização.

Práticas culturais e institucionais de transferência de pacientes do ambulatório para o setor foram vistas como ineficazes. Nestas circunstâncias, o Serviço de Emergência foi percebido como depósito ou "campo de concentração". Considerando que não seja exagerado pensar em responsabilização profissional e culpabilização institucional, reforça-se Que, neste contexto, a equipe de enfermagem, médicos e serviço de segurança são passíveis de um triplo julgamento: o social, o jurídico e o institucional. Assim, há de se considerar um certo reforço na produção de profissionais inseguros, medrosos, sofredores e, conseeüentemente, estressados. Ao mesmo tempo, profissionais disciplinados, vigilantes e controladores.

Além da condição caótica com Que se deparam os serviços de emergência, várias Questões importantes puderam ser evidenciadas ao investigar como a equipe multidisciplinar concebe e transita ante o problema discursivamente objetivado como fuga de pacientes do hospital. Porém, tais resultados acenam para uma lacuna do conhecimento - no mínimo instigante - pois outras respostas e outras compreensões poderiam ser obtidas com o relato daQueles Que fogem. Assim, fica o desafio para Quem venha se interessar pela temática.

\section{REFERÊNCIAS}

I. Conselho Federal de Enfermagem (BR). Decreto $\mathrm{n}^{\circ} 94.406 /$ 87. [citado em 25 jun 2004]. Disponível em: http:// www.portalcofen.com.br/bvirtual/imagemframe.htm

2. Conselho Regional de Enfermagem. Legislação. Porto Alegre: COREN-RS; 1999.

3. Hospital de Clínicas da Universidade de Campinas. Os números do Serviço de Segurança do HC. Campinas; 2002. [citado em II jul 2002]. Disponível em: http://www.hc.unicamp.br/ boletimhcinforma/numero9/materia I 3.htm

4. Hospital de Clínicas de Porto Alegre. Serviço de Emergência. Relatório informativoPorto Alegre: HCPA; 2002.

5. Bauman Z. Modernidade líquida. Rio de Janeiro: Jorge Zahar; 2001 .

6. Foucault M. Vigiar e punir: nascimento da prisão. $23^{\mathrm{a}}$ ed. Petrópolis: Vozes; 2000.

7. Foucault M. A verdade e as formas jurídicas. Rio de Janeiro: Nau; 1999.

8. Foucault M. Resumo dos cursos do Collège de France (19701982). Rio de Janeiro: Jorge Zahar; 1997.

9. Dreyfus HL, Rabinow P. Michel Foucault: uma trajetória filosófica: para além do estruturalismo e da hermenêutica. Rio de Janeiro: Forense Universitária; 1995.

10. Campos GWDS. Um método para análise e co-gestão de coletivos: a constituição do sujeito, a produção de valor de uso e a democracia em instituições: o método da roda. São Paulo: HUCITEC; 2000.

11. Gil AC. Métodos e técnicas de pesquisa social. 5a. São Paulo:
Atlas; 1999

12. Hospital de Clínicas de Porto Alegre. Relatório anual 2002 : o conhecimento a serviço da vida. Porto Alegre: Universidade Federal do Rio Grande do Sul; 2002.

13. Westphal MF, Bógus CM, Faria MM. Grupos focais: experiências precursoras em programas educativos em saúde no Brasil. Bol Oficina Sanitária Panam 1996; 120(6): 472-81.

14. Dall'Agnol CM, Ciampone MH. Grupos focais como estratégia metodológica em pesquisa na enfermagem. Rev Gaúcha Enferm 1999 jan; 20(1): 5-25.

15. Dall'Agnol CM, Ciampone MHT. Avaliação de desempenho: diálogo e representações de um grupo na enfermagem. Rev Bras Enferm 2002; 55(4): 363-70.

16. Lopes CS, Coutinho ESF. Transtornos mentais como fatores de risco para o desenvolvimento de abuso/dependência de cocaína: estudo caso-controle. Rev Saúde Pública 1999; 33(5): 477-86.

17. Carlini-Cotrim B. Potencialidades da técnica Qualitativa grupo focal em investigações sobre abuso de substâncias. Rev Saúde Pública 1996; 30(3): 285-293.

18. Ministério da Saúde (BR). Diretrizes e normas técnicas regulamentadoras de pesquisa envolvendo seres humanos. Brasília (DF): Ministério da Saúde; 1996.

19. Minayo MC. O desafio do conhecimento: peseuisa Qualitativa em saúde. $8^{a}$ ed. São Paulo: HUCITEC; 2004.

20. Polit DF, Beck CT, Hungler, BP. Fundamentos de peseuisa em enfermagem: métodos, avaliação e utilização. $5^{\text {a }}$ ed. Porto Alegre: Artmed; 2004. 
21. Bauman Z. A busca da ordem. In:Bauman Z. Modernidade e ambivalência. Rio de Janeiro: Jorge Zahar; 1999. p. 9-26.

22. Bittar OIN. Indicadores de Qualidade e Quantidade em saúde parte 2. Rev Admin Saúde 2004; 6(22): 15-8.

23. Perez J. Emergency room. In: Perez ON. US National Library of Medicine; 1998. [cited on 2005 ago 23]. Available in: http://babelfish.altavista.com/babelfish/

24. Superior Tribunal de Justiça. Processo: Resp 602 101/RS; Recurso Especial 2003/0192193-2. Julgamento em 06/04/ 2004. In: Supremo Tribunal de Justiça. Jurisprudência/STJ.
Brasília: Ministério da Justiça; 2005.

25. Conselho Regional de Medicina de São Paulo. Consulta no. 23.606/97. [citado em II set 2005]. Disponível em: http:// www.cremesp.com.br/legislação/pareceres/parcrm/ 23606_1997.htm.

26. Nalini JR. Responsabilidade ético-disciplinar do médico: suspensão e cassação do exercício profissional. In: XII Encontro dos Conselhos Regionais de Medicina das Regiões Sul e Sudeste. 2001. São Paulo (SP), Brasil. São Paulo: Conselho Regional de Medicina; 2001. 